\title{
Food Fraud Prevention: Policy, Strategy, and Decision-Making - Implementation Steps for a Government Agency or Industry
}

\author{
John Spink ${ }^{\star a}$, Neal D. Fortin ${ }^{b}$, Douglas C. Moyer ${ }^{c}$, Hong Miao ${ }^{d}$, and Yongning Wu
}

\begin{abstract}
This paper addresses the role of governments, industry, academics, and non-governmental organizations in Food Fraud prevention. Before providing strategic concepts for governments and authorities, definitions of Food Fraud are reviewed and discussed. Next there is a review of Food Fraud activities by the Global Food Safety Initiative (GFSI), the Elliott Review in the United Kingdom, the European Commission resolution on Food Fraud, and the US Food Safety Modernization Act including the Preventative Controls Rule. Two key concepts for governments or a company are: (1) formally, and specifically, mention food fraud as a food issue and (2) create an enterprise-wide Food Fraud prevention plan. The research includes a case study of the implementation of the concepts by a state or provincial agency. This analysis provides a foundation to review the role of science and technology in detection, deterrence and then contributing to prevention.
\end{abstract}

Keywords: Authenticity · Economically motivated adulteration $\cdot$ Food crime $\cdot$ Food fraud $\cdot$ Policy

\section{Introduction}

This paper addresses the role of governments, industry, academics, and nongovernmental organizations in Food Fraud prevention. This question has grown in prominence and importance in recent years due to food scandals that have reduced consumer confidence. This paper also reviews the role of science and technology in detection and deterrence, and accordingly, prevention.

Food Fraud - the illegal deception for economic gain using food - is a vital and emerging concern of governments, industry and consumers. Consumer awareness was heightened after a series of high-pro-

${ }^{\star}$ Correspondence: Dr. J. Spink

E-mail: spinkj@msu.edu

aMichigan State University (USA)

College of Veterinary Medicine, Food Fraud Initiative East Lansing, Michigan, USA

bMichigan State University (USA)

College of Agriculture and Natural Resources

Food Science and Human Nutrition;

College of Law, Institute for Food Laws and

Regulations

East Lansing, Michigan, USA

cMichigan State University (USA)

College of Human Medicine

Division of Public Health

East Lansing, Michigan, USA

${ }^{d}$ Chinese National Center for Food Safety

Risk Assessment (CFSA)

Beijing, China file incidents including: melamine in pet food and infant formula, horsemeat in beef, and repetitive incidents of seafood species substitution. A more recent and dangerous example is peanut shells - an allergenic adulterant-substance - being added to dilute ground cumin for economic gain.

The European Commission (EC) identifies Food Fraud as a 'top-5 issue' for the overall European economy not just for the food industry. ${ }^{[1]}$ The Chinese food safety authorities continue to emphasize Food Fraud prevention during official international presentations. ${ }^{[2,3]}$ The US Food Safety Modernization Act (FSMA) has a specific section 418 referred to as the Preventative Controls Rule (FSMA-PC). This requires that food establishments create a written hazard analysis and riskbased preventative control (HARPC) plan, which includes preventative controls that address 'economically motivated adulteration' (EMA) or hazards from economically motivated acts. ${ }^{[4,5]}$ Both the US Government Accountable Office (GAO) and US Congressional Research Service (CRS) issued reports on Food Fraud. These emphasize that Congress and consumers clearly hold state and federal food agencies accountable for preventing Food Fraud regardless of formal laws, regulations, standards, or certifications. ${ }^{[6,7]}$

Industry has also identified Food Fraud as an important concern. The Global Food Safety Initiative (GFSI) - an industry-led standards and certification body - has identified it a 'top-5 issue'. ${ }^{[8]}$ The GFSI food safety management system is requiring, auditing, and certifying that all industry must implement a Food Fraud vulnerability assessment and a Food Fraud Mitigation Plan. This research article reviews the fundamental issues, presents concepts for government agencies and explores a case study application for a state.

\section{Background}

\subsection{Food Fraud Definitions and Prevention}

Food Fraud is defined by a wide range of organizations generally as "deception for economic gain using food."[9] This definition is broadly adopted internationally and by industry standards-setting organizations. ${ }^{[2,3,10-12]}$ A full definition is from Spink \& Moyer, 2011:[9]

"Food fraud is a collective term used to encompass the deliberate and intentional substitution, addition, tampering, or misrepresentation of food, food ingredients, or food packaging; or false or misleading statements made about a product, for economic gain. Food fraud is a broader term than either the economically motivated adulteration (EMA) defined by the Food and Drug Administration (FDA) or the more specific general concept of food counterfeiting."

The range or scope of the types of Food Fraud is included in Table 1.

Two primary drivers for Food Fraud policy are the DEFRA Elliott Review 
Table 1. Food Fraud Types, Definitions, and Examples

\begin{tabular}{|c|c|c|}
\hline Term & Definition & Example \\
\hline $\begin{array}{l}\text { Adulteration } \\
\text { (adulterant- } \\
\text { substance) }\end{array}$ & $\begin{array}{l}\text { A component of the finished } \\
\text { product is fraudulent; a substance } \\
\text { or an impurity }\end{array}$ & Melamine added to milk \\
\hline Tampering & $\begin{array}{l}\text { Legitimate product and packaging } \\
\text { are used in a fraudulent way }\end{array}$ & $\begin{array}{l}\text { Changed expiry information, } \\
\text { product up-labeling, etc. }\end{array}$ \\
\hline Over-run & $\begin{array}{l}\text { Legitimate product is made in } \\
\text { excess of production agreements }\end{array}$ & Under-reporting of production \\
\hline Theft & $\begin{array}{l}\text { Legitimate product is stolen } \\
\text { and passed off as legitimately } \\
\text { procured }\end{array}$ & $\begin{array}{l}\text { Stolen products are co- } \\
\text { mingled with legitimate } \\
\text { products. }\end{array}$ \\
\hline Diversion & $\begin{array}{l}\text { The sale or distribution of } \\
\text { legitimate products outside of } \\
\text { intended markets }\end{array}$ & $\begin{array}{l}\text { Relief food redirected to } \\
\text { markets where aid is not } \\
\text { required }\end{array}$ \\
\hline Simulation & $\begin{array}{l}\text { Illegitimate product is designed to } \\
\text { look like but not exactly copy the } \\
\text { legitimate product }\end{array}$ & $\begin{array}{l}\text { 'Knock-offs' of popular foods } \\
\text { not produced with same food } \\
\text { safety assurances }\end{array}$ \\
\hline Counterfeiting & $\begin{array}{l}\text { Intellectual Property Rights (IPR) } \\
\text { infringement, that could include } \\
\text { all aspects of the fraudulent } \\
\text { product and packaging being } \\
\text { fully replicated }\end{array}$ & $\begin{array}{l}\text { Copies of popular foods not } \\
\text { produced with same food } \\
\text { safety assurances }\end{array}$ \\
\hline
\end{tabular}

(UK), the Global Food Safety Initiative (GFSI) Food Fraud Think Tank, and the European Commission (EC). The EC has also created a common definition of Food Fraud and created Food Fraud Networks for the member States. China has expanded their Food Safety laws to directly address Food Fraud by separating section on 'traditional' and 'non-traditional' risks. The UK and GFSI definitions will be reviewed in more detail.

\subsubsection{Global Food Safety Initiative (GFSI)}

The Global Food Safety Initiative (GFSI) published a report entitled 'GFSI Position on Mitigating the Public Health Risk of Food Fraud.' [12] The report includes the GFSI's definition of Food Fraud:

"Food fraud... is deception of consumers using food products, ingredients and packaging for economic gain and includes substitution, unapproved enhancements, misbranding, counterfeiting, stolen goods or others." $[12]$

Based on this definition, the GFSI compliance will require a Food Fraud Vulnerability Assessment and Food Fraud Mitigation Plan. GFSI requirements are stated in guidelines published by the SSAFE[13] organization. This guideline is publically available as a report and an online tool was created for SSAFE by PriceWaterhouseCoopers (PWC). SSAFE's adaptation of the Food Fraud definition is:

"In the [SSAFE Food Fraud] guideline, food fraud refers to intentional food adulteration (i.e. dilution, substitution, concealment, unapproved enhancements, mislabeling) and counterfeiting for economic reasons. Ideologically motivated acts (i.e. food defence), and unintentional safety-related incidences in the food Supply chain are out of scope of this guideline."[14]

\subsubsection{European Commission (EC)}

The European Commission followed up on the 2012 horsemeat fraud incident by drafting and then approving a resolution on Food Fraud. One key finding was that Food Fraud was not previously defined. The EC proposed and approved the following definition:

"According to Spink and Moyer 'Food fraud is a collective term used to encompass the deliberate and intentional substitution, addition, tampering, or misrepresentation of food, food ingredients, or food packaging; or false or misleading statements made about a product for economic gain'. Drawing on from this definition the key characteristics of food fraud are: 1) non-compliance with food law and/or mis- leading the consumer, 2) which is done intentionally and 3) for reasons of financial gain."[11]

\subsubsection{UK Food Standards Agency and the Elliott Review}

The Elliott Review was a 2014 assessment of Food Fraud - referred to also as Food Crime - directed and funded by the UK Department for Environment, Food and Rural Affairs (DEFRA). ${ }^{[10]}$ The Elliott Review first noted the UK Food Standards Agency's existing definition of Food Fraud:

"Food fraud is defined by the Food Standards Agency as: deliberately placing food on the market, for financial gain, with the intention of deceiving the consumer.... Food fraud may also involve the sale of meat from animals that have been stolen and/or illegally slaughtered..."[10]

The Elliott Review provided additional detail which cited Spink \& Moyer:[9]

"Food fraud encompasses deliberate and intentional substitution, addition, tampering, or misrepresentation of food, food ingredients, or food packaging; or false or misleading statements made about a product for economic gain. The types of fraud include adulteration, tampering, product overrun, theft, diversion, simulation, and counterfeiting." $[10]$

The Elliott Review was funded to address the consumer confidence crisis. The report was scoped to review the danger and then research or envision the functional food fraud prevention framework. The report is not a bill or law so it does not include additional resource-allocation for the agencies that will be responsible for the implementation. The Elliott Review provides "eight pillars of food integrity" and outlines the infrastructure implement a "national food crime prevention framework" in eight specific recommendations. ${ }^{[10}$

The review included eight very specific recommendations:[10]

- "Recommendation 1 - Consumers

First: Government should ensure that the needs of consumers in relation to food safety and food crime prevention are the top priority.

- Recommendation 2-Zero Tolerance: Where food fraud or food crime is concerned, even minor dishonesty must be discouraged and the response to major dishonesty deliberately punitive.

- Recommendation 3 - Intelligence Gathering: There needs to be a shared focus by Government and industry on intelligence gathering and sharing.

- Recommendation 4 - Laboratory Services: Those involved with audit, inspection and enforcement must have access to resilient, sustainable laboratory services that use standardised, validated approaches. 
- Recommendation 5-Audit: The value of audit and assurance regimes must be recognised in identifying the risk of food crime in supply chains.

- Recommendation 6 - Government Support: Government support for the integrity and assurance of food supply networks should be kept specific, measurable, attainable, realistic and timely (SMART).

- Recommendation 7 - Leadership: There is a need for clear leadership and co-ordination of effective investigations and prosecutions relating to food fraud and food crime; the public interest must be recognised by active enforcement and significant penalties for serious food crimes.

- Recommendation 8 - Crisis Management: Mechanisms must be in place to deal effectively with any serious food safety and/or food crime incident."

The concepts proposed in this article are developed after considering global activities such as the Elliott Review. The concepts in this research do not conflict with the Elliott Review. The concepts in this research build up on the Elliott Review and provide a method for implementing Food Fraud prevention.

\subsubsection{US Food and Drug Administration (FDA)}

The FDA does not specifically use the term 'Food Fraud'. The nearest derivation is 'Economically Motivated Adulteration' (EMA). EMA was first used in a Federal Register meeting notice for the May 2009 Public Meeting on Economically Motivated Adulteration as a "fraudulent, intentional substitution or addition of a substance... for economic gain." The meeting notice stated:

"For purposes of this [May 2009] public meeting, FDA proposes a working definition of EMA as the fraudulent, intentional substitution or addition of a substance in a product for the purpose of increasing the apparent value of the product or reducing the cost of its production, i.e., for economic gain. EMA includes dilution of products with increased quantities of an already-present substance (e.g., increasing inactive ingredients of a drug with a resulting reduction in strength of the finished product, or watering down of juice) to the extent that such dilution poses a known or possible health risk to consumers, as well as the addition or substitution of substances in order to mask dilution." [15]

This is the most recent FDA definition of Food Fraud as it has not been updated or addressed anywhere including in FSMA. It is important to note that the original FSMA law, written by Congress, did not include the term EMA and only addressed inten- tional adulteration' which was later clarified to be Food Defense such as terrorism. FDA is not barred from using, or expanding to, using the Food Fraud term.

The first step in the Food Fraud prevention foundation and concept are the definitions. The next step is to understand prevention.

\subsection{Food Fraud Prevention}

Since there are so many types of fraud, fraudsters and offender organizations is it more efficient to focus on changing the 'space' of crime rather than the criminals. ${ }^{[16-18]}$ It has been stated that "we will not arrest our way to safety" and "we will not test our way to safety." The prevention focused approach is based on very fundamental Criminology and Crime Science theories. Specifically, crime prevention focuses on reducing the opportunity or motivation to conduct a crime. This has been widely researched in 'environmental criminology' subjects such as Situational Crime Prevention and Routine Activities Theory. ${ }^{[19-23]}$ The other criminology perspective is 'traditional criminology' that focuses more on individual criminals.

Several initiatives and regulations focus only on health hazards of Food Fraud. Organizations such as the FDA have statutory direction to focus on public health. Therefore it is logical and efficient for a food agency to focus on the health hazards associated with Food Fraud rather than fully on all economic vulnerability. This health-based risk approach de-emphasizes the economic impact of Food Fraud incidents. This leaves non-food agencies to focus on the economic crime aspect of Food Fraud. In the US these include the Federal Bureau of Investigation (FBI), US Customs and Border Patrol (CBP), or Department of Commerce (DOC). Often, related to other types of crimes, the economic impact of Food Fraud incidents are commonly very small.

That said, the potential economic impact of a single Food Fraud incident can be extremely costly for a company, industry, or country. For example, the Grocery Manufacturers Association (GMA) estimates that one 'consumer product fraud' incident could cost $2-15 \%$ of a company's annual profit. ${ }^{[24]}$ In most cases brand owners and retailers are also deceived and as victims they are also severely and negatively impacted. For these reasons Food Fraud prevention must be a prioritized enterprise risk for companies, industries, and countries alike. Enterprise Risk Management (ERM) provides insight and priority setting methods that can be applied to the analysis of known and unknown Food Fraud risks.

Once Food Fraud prevention is identified as a priority, there is a question of how to categorize or sort the range of food risks. A system is needed to define who is accountable and responsible for managing and implementing Food Fraud prevention plans.

\subsection{Food Fraud Incidents}

There is a wide range of documented Food Fraud incidents. The economic impact of Food Fraud incidents can be very high and even incapacitate an industry. For example, the 2013 US honey smuggling incident was estimated at US\$40 million in lost taxes. In another incident, a food quality fraud was estimated at US\$400 million over 10 years. ${ }^{[25]}$

The vast majority did not have a public health threat even though there is always vulnerability for a food safety hazard. When fraud is conducted there is a vulnerability that dangerous adulterant-substances have been added or the product has been mishandled and has become dangerous. For example, there were many deaths and illnesses from melamine in infant formula. Also, a genuine but stolen product could be mishandled leading to foodborne illness from pathogens. The FDA understood this and stated, "...despite longstanding FDA requirements to assure the safety of regulated products, such as requirements for the use of ingredients of known identity and quality in drugs, economically motivated adulteration remains a public health threat.', $[15]$

The original FDA EMA public meeting covered all FDA products and food and drug fraud examples are listed below. ${ }^{[15]}$ This list demonstrates the broad focus of FDA on a range of consumer products and also their efforts for collaborative countermeasures.

- Melamine adulterant-substance in pet food and infant formula (animal food)

- Synthetic chemical adulterant-substance in Heparin instead of pig intestines (drug)

- Melamine adulterant-substance in infant formula and other milk products (human food)

- Diethylene glycol adulterant-substance in cough syrup and other drugs (drug)

Beyond the incidents mentioned at the FDA meeting, a broader range of Food Fraud incidents include:

- Sudan Red carcinogen colorant in paprika and other spices (adulterantsubstance)

- Horsemeat in beef (adulterant-substance)

- Peanut Corporation of America selling product with known bacterial contamination (tampering)

- Smuggled honey and origin laundering for tax avoidance (diversion)

- Stolen raw poultry re-introduced to the supply chain (theft) 
- Ground peanut shells used to extend cumin (adulterant-substance)

Collecting Food Fraud incident data can be challenging as there often is no specific or defined recall category or seizure databases. In other instances, such as the RASFF system, intentional and unintentional acts may be in the same dataset (whether intentional or not, mislabeling is fraud). There are several Food Fraud incident databases that include the US Pharmacopeia (www.FoodFraud.org), the National Center for Food Protection and Defense (www.ncfpd.org), and the EC Rapid Alert System for Food and Feed (RASSFF, http://ec.europa.eu/food/safety/ rasff/index_en.htm).

Only after the differing Food Fraud definitions and Food Fraud types are understood - along with the available incident databases - can a focus on prevention be established. The next step is to review detection, deterrence, and prevention options. This is where science and technology have a critical role. There is also a critical and complex role for data gathering and intelligence analysis.

\subsection{Role of Science and Technology}

The science and technology is applied to detection with a focus on contributing to prevention. Before addressing what science or technology is needed to detect Food Frauds, there must be a review of known incidents to determine what contributes to the fraud opportunity. The goal is not to catch or detect every fraudulent product but to prevent them from ever entering the supply chain. From a recent article by Spink, Elliott and Swoffer:

"The goal of a Food Fraud prevention programme, including a HACCP type approach, which builds on the benefits of Food Safety and Food Defence programmes, is to create a system that prevents fraudsters from wanting to attack. The goal of a Food Fraud programme is to implement process controls to reduce the opportunity for unknown contaminants to enter the supply chain and to support prevention by reducing the fraud opportunity."[26]

Detection is finding a specific adulterant-substance or product anomaly. Deterrence is a targeted countermeasure to stop one specific type of Food Fraud or fraudster. Prevention is the application of countermeasures that reduces the fraud opportunity. Food Fraud detection, deterrence and prevention is very challenging and often involves very different assessments and technologies. More details of the complexity are noted here:

"There are complexities to authenticating food that are unlike any other sciences - the complexity of profiling a multicomponent food product requires meth- odologies than are still far from routine and easy to use and interpret. There is an incredible amount of inherent variation in the same food product produced over the course of a year."[26]

There are specific questions that should be addressed when assessing the effectiveness of a specific technology or system countermeasure. ${ }^{[27]}$ To note, brand and product protection managers prefer the term 'countermeasure' versus 'solution' since they say the problem cannot be solved but only addressed. The use of 'countermeasure' is also efficient since fraud prevention is more like managing a chronic disease like diabetes than healing an injury such as an acute incident such as a broken leg. There is a need to constantly monitor the marketplace since the fraudsters will continue to seek ways to commit fraud. To address this shifting vulnerability, specific questions that address the efficacy of potential countermeasures include:

- "What does the countermeasure do?

- How exactly does the countermeasure detect and deter specific types of fraudster?

- How does the countermeasure compare to what other people do? What are the other countermeasures or other suppliers of this specific product?

- What are the benefits and drawbacks of those other countermeasure or other suppliers?

- Is the countermeasure ready to trial or implement immediately?

- How would those specific types of fraudsters try to defeat or circumvent the system?

- Where has this technology been implemented before? What types of products, geography, breadth of implementation and does the supplier have press releases or references?

- How will fraudsters try to circumvent this countermeasure?"[27]

The most complex and challenging aspect of Food Fraud prevention is the detection. Considering the known incidents and attributes of the fraud opportunity can help specify the precision, accuracy, can certainty need when developing or selecting countermeasures. To achieve the optimal Food Fraud system or countermeasure there must first be a focus on prevention from a review of the fraud opportunity.

\subsection{Laws, Regulations, Standards and Certifications}

This section will review the most impactful and direct Food Fraud related compliance requirements which are GFSI and FSMA. There are other important requirements - such as the Chinese Food Safety Laws, the activity in the United Kingdom, and by the European Commissions - but their scope and requirements are not as fully defined.

\subsubsection{Food Safety Modernization Act (FSMA)}

While there is currently no over-arching Food Fraud regulation in the United States, the Food Safety Modernization Act (FSMA) has provisions that address many Food Fraud aspects. FDA has other laws or regulations that address other types of fraud such as stolen goods, counterfeiting, smuggling, mislabeling, and tampering. The original FSMA law written by Congress did not specifically mention or address EMA. EMA was only directly mentioned in the rulemaking by FDA. To be compliant with FSMA the FDA does not need to explicitly address EMA and could evolve to use the Food Fraud term.

In September 2015, rulemaking for the FSMA Preventative Controls final rule (FSMA-PC) was finalized and published. FSMA-PC mentions the term 'Economically Motivated Adulteration' but it is undefined. The common abbreviation EMA is not used in FSMA-PC but is used in later FSMA final rules (there are seven rules total). Additionally FSMA-PC does not mention or define Food Fraud. The word 'adulterant' was also not mentioned in the entire $1600+$ pages of the human and animal rules.

The FSMA-PC Final Rule clearly requires a vulnerability or risk assessment of 'economically motivated' actions that could cause a health hazard. The document refers to 'agents' (probably meaning 'physical agents') that could be from many sources not explicitly intentionally added (e.g. spoilage would be an 'agent' in stolen genuine goods that were mishandled). Subsequent prevention plans are also required where warranted. The lack of additional details broadens the rule's scope to include all types of Food Fraud and not just adulterant-substances.

Of significance, FSMA-PC compliance does not equate to compliance with all of FSMA or other existing food regulations. For example, there is a separate section in FSMA dealing with 'Smuggled Foods'. Also, FSMA compliance does not equate to compliance with all FDA laws. For example, the Food, Drug \& Cosmetics Act of 1938 (FDCA) is repeatedly mentioned throughout FSMA and still covers 'Adulterated Foods' which includes Food Fraud types such as stolen goods. Additionally, other US laws and regulations apply which are administered by other agencies (e.g. the Consumer Protection Commission, US Customs and Border Patrol, US Chamber of Commerce, etc.) (Fig. 1). Beyond FSMA, the FDCA specifically addressed Food Fraud types in the 'Adulterated Food' and 'Misbranded 
Foods' sections. Specifically, the preamble of the Michigan Food Law of 2000 (MCL 289.1101) stated the intent to "prevent fraud and deception." Additionally, US State laws also cover some aspects of Food Fraud such as the 'comminuted meats' section of the Michigan Food Code.

To expand on the compliance requirements, FSMA-PC requires "economically motivated" acts be addressed via vulnerability assessments and risk mitigation plans. But the question of exactly which Food Fraud types are (or are not) required for assessing is generally a moot point. That is due to most food companies addressing all Food Fraud types through the vulnerability assessment and risk prevention requirements to be GFSI compliant. The acceptance - or at least recognition of GFSI audits is already in the FSMA Accredited Third Party Final Rule. Other parts of FSMA also address and support third-party audits including the GFSI system that is recognized (at least in public statements by senior USFDA leadership) as a valid third-party certification.

\subsubsection{Global Food Safety Initiative (GFSI)}

In addition to US laws, the food industry is subject to standards and certifications such as those approved by the GFSI. Originally GFSI was created by a group of industry Chief Executive Officers from the Consumer Goods Forum to help optimize and harmonize food safety standards. Due to this broad engagement and commitment, GFSI is the most impactful industry initiative. Scheme Owners - such as BRC Global Systems (BRC), Food Safety System Certification (FSSC), and others develop food safety standards. Auditing bodies - such as NSF International and others - certify that food manufacturers meet the requirements of GFSI approved audit schemes. The auditors are defined as accredited third-party auditors. [28]

The GFSI efforts began by considering the wide variety of regulations that were required by different countries and companies. GFSI worked to create requirements that covered those regulations and standards which are presented in the 'GFSI Guidance Document'. This document details 'The Idea' or expected scope (Fig. 2).

Next, standard setting organizations called 'Scheme Owners' create 'The Standard'. Then manufactures and producers implement the standards. Finally, there are certification bodies or auditors that conduct Third-Party Audits to certify the standards are being properly implemented (noted in Fig. 2 as Confirmed). Ultimately, if a government requires 'a' process for conducting a Food Fraud Vulnerability Assessment and mitigation/ prevention plan, then a mechanism would already be

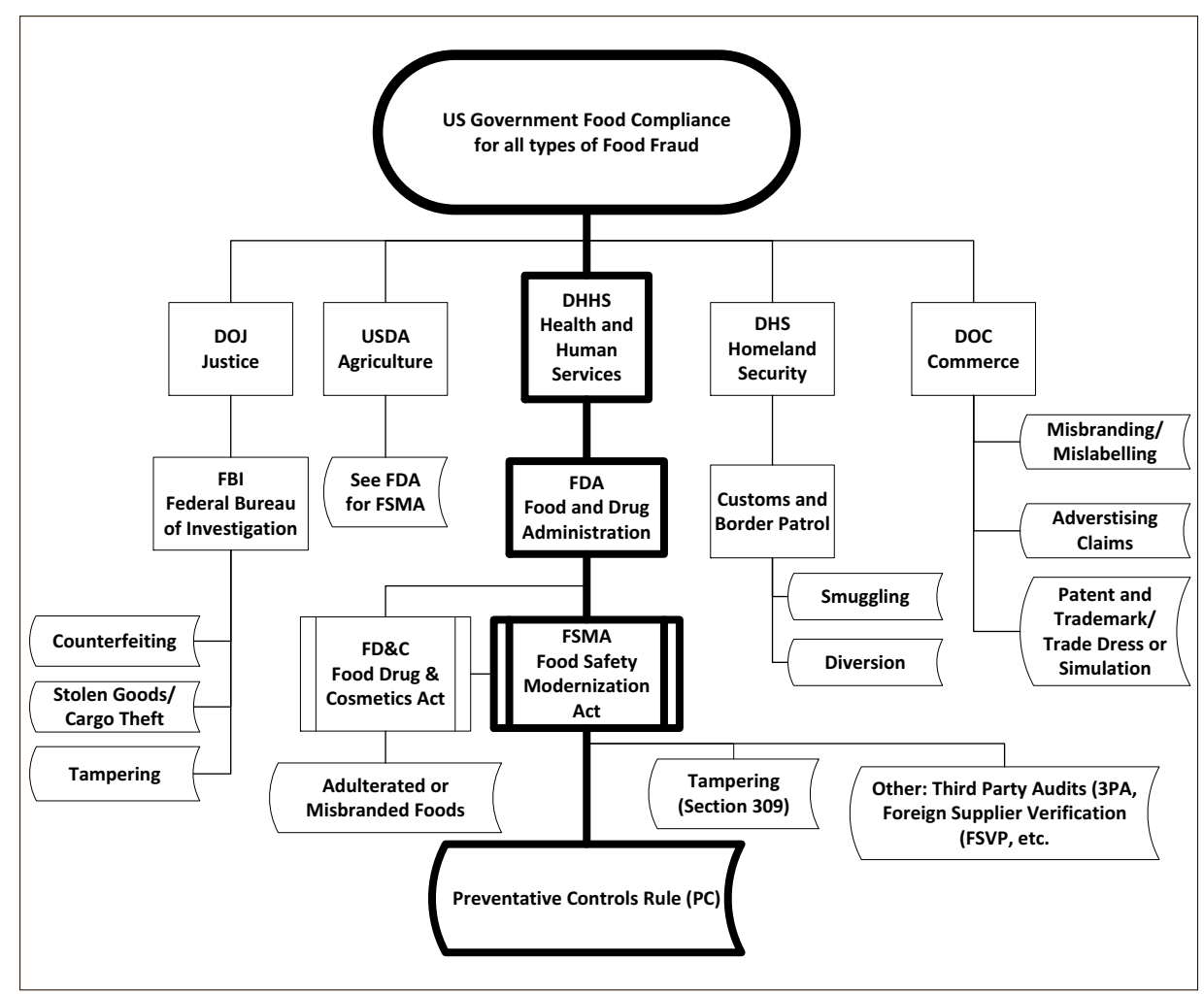

Fig. 1. Hierarchy of US Government Compliance from the FSMA PC Rule to Other.

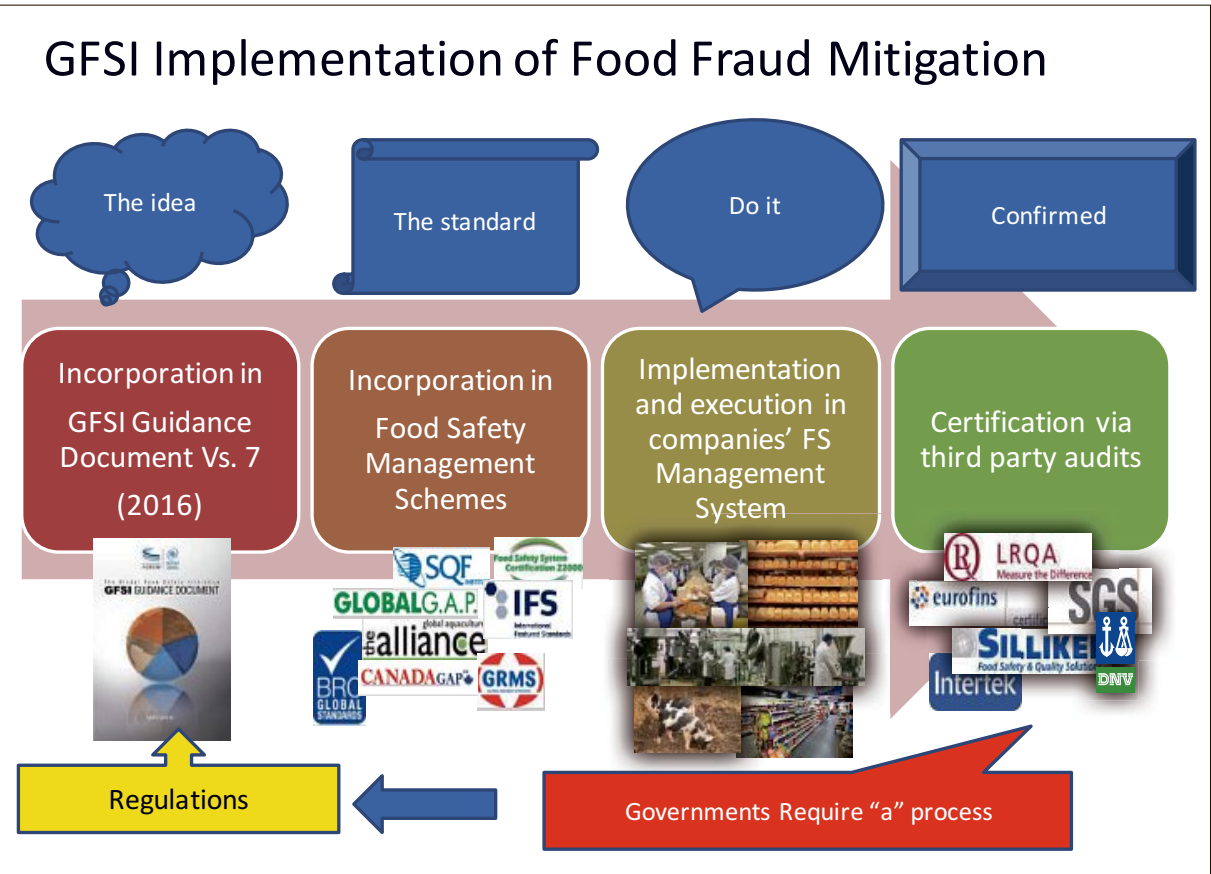

Fig. 2. Global Food Safety Initiative (GFSI) system for the Food Safety Management System, Implementation, Certification, and Contribution to Regulations. Original figure produced with permission.

in place and the regulation would just reinforce the process. The government would be requiring 'a' process and would not be explicitly endorsing GFSI or any other system.

In 2012, GFSI created a Food Fraud Think Tank that published its Position Paper on Food Fraud Prevention that was adopted by the GFSI Board of Directors in 2013. GFSI will include Food Fraud re- quirements in the next guidance document due to be published in 2016 and formally required in 2017. Even before that formal adoption - as early as June 2015 - and based on insight from the Position Paper, some Scheme Owners have started to audit the Food Fraud prevention requirements.

The key GFSI Food Fraud requirements are: Food Fraud Vulnerability Assessment and a Food Fraud Mitigation Plan. 


\section{Concepts for Government Food Agencies}

There is no legal or regulatory requirement for a US federal or state agency to directly address 'Food Fraud'. There are FSMA requirements for food producers and distributors to implement prevention plans for "known or reasonably foreseeable" health hazards that are "economically motivated." Clearly the legislature, consumers, and citizens expect the foodregulating agencies to manage and prevent food-related concerns such as those posed by all types of Food Fraud. While the US has experienced Food Fraud incidents, none have undermined consumer confidence to the extent of fraud that happened with horsemeat in the UK (and EU) with horsemeat in beef and in China with melamine in infant formula.

US states typically have a myriad of food safety laws that apply even though they may not have a singular Food Fraud law. Thus, States probably do not need to create new laws, they need to identify the range of laws that apply to Food Fraud generally. Moreover, a significant concern for any government agency is any mandate for any new or expanded regulatory activity. New plans or expansion of scope should consider that there will probably be no - or little - additional resource allocation or funding for inspection, enforcement, and prosecution. For any expanding or new regulations it will be important to incorporate and leverage current activities.

Overall, for any new, emerging issue without federal law precedence, there are a range of responses for a state. The concepts for a state food agency can be viewed as a continuum ranging from doing nothing to creating a new law (see Fig. 3).
The research discloses strategic gaps regarding Food Fraud. Regardless of whether new regulations are used to fill the gaps, these represent opportunities for-at the very least-new policies to shape future actions. These following concepts have been developed for Federal or State governments but they readily apply to corporate policy.

\subsection{Concept One: Formally, and Specifically, Mention Food Fraud as a Food Safety Issue}

In order to prevent economically motivated health hazards, government should formally and holistically address all types of Food Fraud, not just adulterant-substances. For the US Federal Government this would include expanding the explanation that is included in FSMA-PC and the other final rules. Even cursory efforts to address Food Fraud - e.g. a guidance document or statement confirming an expectation that companies should have a risk assessment and mitigation plan to address hazards including Food Fraud - would increase the industry response or at least support the current focus on industry led standards. An example of an agency policy statement created here is:

"This statement confirms that AGENCY expects the food industry to conduct risk or vulnerability assessments, including mitigation or prevention plans where warranted, on all incidents that could lead to a health hazard or the violation of a food law such as the FSMA or the FD\&C. This includes all Food Fraud such as adulterantsubstances, tampering, theft, illegal diversion or gray markets, illegal mislabeling, and intellectual property rights or product counterfeiting, and others. Consistent with existing Federal and State laws and regu- lations, third-party certifications play an important role in supporting this type of food supply chain protection."

Before reviewing the Food Fraud prevention structure it is important to review previous related activities. Prevention is over-arching strategies that reduce the potential for a type of incident to occur. A prevention focus contrasts with a compliance focus. A compliance focus only addresses supply chain participants meeting regulatory or standards requirements often a prescriptive set of steps - rather than focusing on reducing the risk. For example, Michael Taylor, FDA Deputy Commissioner for Foods and Veterinary Medicine, frequently mentions that the goal is safe food not just compliance.

Additionally a prevention focus is proactive and not reactive detection or enforcement (and related prosecution and punishment). While enforcement activities are critical, they only play a small and often inefficient role in prevention. This is consistent, and based upon, several criminology theories including Situational Crime Prevention, Routine Activities Theory, and Rational Choice Theory.

It is logical that when a new food incident occurs - especially an unusual type of incident such as a Food Fraud - the response is initiated in the Intervention stage (Fig. 4). For example, when there is a new health hazard the first step is to identify and understand the root cause. The Response step includes actions such as removing the product from the marketplace and pursuing enforcement and prosecution. Once the crisis passes, the final step is a shift to Prevention that minimizes the potential for recurrence. This process requires an active monitoring system to detect new or evolving threats.

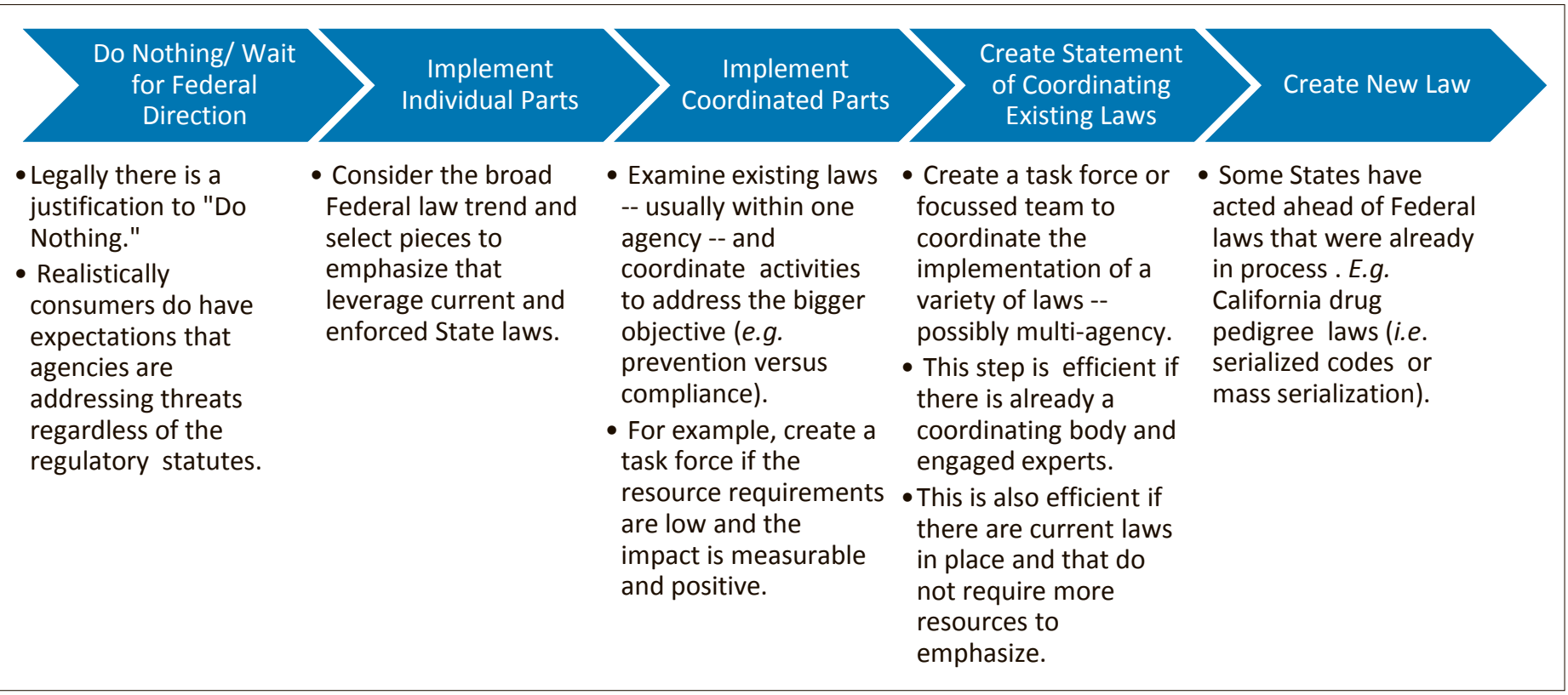

Fig. 3. Continuum of State responses to new or evolving issues without a Federal precedence. 


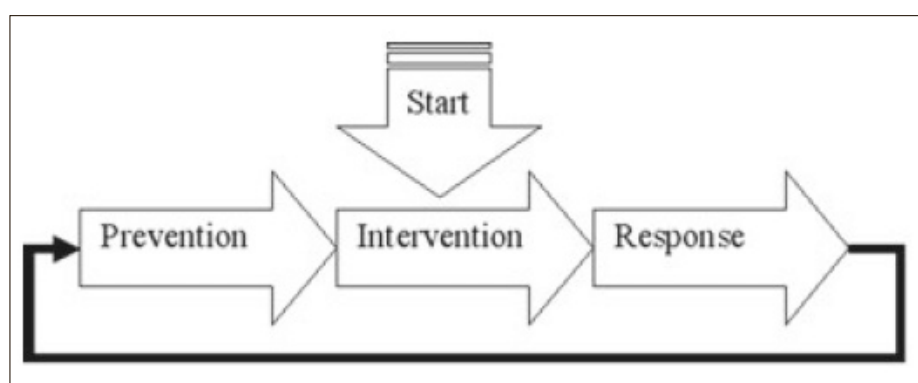

Fig. 4. Food

Protection Plan

Progression (reprinted with permission of John Wiley and Sons Inc., 2011, from ref. [9]).
This is essentially the application of Quality Management Principles to a government where the focus is resolving root cause rather than fixing the problem.

\subsection{Concept Two: Create a Government-wide Food Fraud Prevention Plan}

Prevention not only requires overarching strategies but also the system-wide commitment to a plan. This includes the regulatory agencies of a government as well as all resources of a food producer. This is illustrated in the following case study included for a state agency to address Food Fraud.

\section{Case Study of Implementation}

A government-wide Food Fraud prevention plan is defined by several steps. The concepts stated above are included with direct reference to a state agency Food Protection Workgroup (WG). For example, under the FDA Food Defense Innovation Grant program, the State of Michigan's Department of Agriculture and Rural Development has funding to support a public-private partnership that addressed Food Protection and Food Defense. This group is the Michigan Food \& Agriculture Protection and Defense Working Group. This group has covered Food Fraud or EMA under the past scope and mission of the FDA Food Defense programs. In part this scope has been maintained due to expertise and interest by the team members including the authors of this research.

These concepts consider the resources and ongoing activities within the state. The concepts are efficient for government and industry since the plan is consistent with the federal FSMA requirements and are already being addressed by industry under the GFSI Food Fraud activities. The concepts apply to the prevention plan which is then defined by a series of steps.

\subsection{Plan Development}

While Food Fraud is just being defined or mentioned in laws and regulations, the most basic risk assessments are only now being devised and conducted. A major con- cern is how governments and industry will address identified risks. Developing a plan must consider a balance between resources constraints (i.e. inspection and oversight) as well as optimizing the current public and private activities.

It is important to note that in many states such as Michigan no new laws or regulations are required to holistically address all types of Food Fraud. All types of Food Fraud being addressed by a variety of the state agency and other state agency regulations. The concepts and plans presented below enable a state agency to efficiently and holistically establish a Food Fraud strategy prevention plan.

\subsubsection{Create a Task Force or Workgroup}

This step is to 'Create a Task Force or Workgroup' to review the emerging issue of Food Fraud. During the development stage it is important to specify an ongoing review process.

\subsubsection{Preparation: Internal and External}

This step is the 'Preparation-Internal' step which includes reviewing internal information or reports.

- Review Policies and Programs: Review the national and international activities of governments and industry.

- Review Related State Laws: Review the current State laws and the responsible agencies that apply to the full range of Food Fraud incidents.

- Incident Review: Review known incidents within the State. Also this should include a review incident for similar products (e.g. apple juice and cherry juice).

- Incident Clustering Review: Review the known incidents and analyze for activity clusters.

- Food Fraud Vulnerability Assessment (FFVA): Review the fraud opportunity by applying Environmental Criminology concepts of Situation Crime Prevention to better understand the 'space' of crime. An example of this is described in 'Defining the Public Health Threat of Food Fraud' [9] and applied to a government in 'Review of the Nigerian Combating Counterfeit
Medicines Initiative.' [29] This methodically assesses the fraud opportunity and is a system for reviewing the potential efficacy of countermeasure in reducing the fraud opportunity.

- Food Safety Risk Assessment (Decision-Making Mechanism): Assess the public health hazards of Food Fraud with respect to other agency priorities. A defined process for reviewing and prioritizing agency resources already exists. In industry this is Enterprise Risk Management (ERM) and is based on COSO accounting principles. Of note, an enterprise can also be a government.

This step is the 'Preparation-External' which includes reviewing external information or reports.

- Industry Incident Survey: Survey industry (confidentially) for any suspicious activity.

- Industry Status Survey: Survey companies located in the state for their use or application of Food Fraud Vulnerability Assessments and Food Fraud Prevention Plans (e.g. GFSI compliance). While not yet a formal statement, policy, or rule, simply posing the question raises this issue within industry. This spurs industry focus on Food Fraud-and if industry-wide efforts are efficient-increases the safety of food products in a state.

\subsubsection{Intervention and Response}

While it is still very early in the process, it is important to begin to envision potential countermeasures and prevention activities. For example, Food companies should eventually be required by the State to implement these programs. There is precedence for the concepts already under FSMA and the same concepts are being developed and are required by industry under the GFSI certification. These are not new programs that will need to be developed or managed by the state. Also, vulnerability assessments and mitigation plans will be required by industry anyway. Stating the requirements by the state will only further emphasize the importance of the concepts and support protecting the consumers.

- The state should clarify these compliance requirements for industry specifically under existing food regulations:

o Require a Food Fraud Prevention Policy, Strategy, or Program

- Require a Food Fraud Vulnerability Assessment

o Require a Food Fraud Prevention Plan

o Require Management Commitment (i.e. similar to Food Safety HACCP requirements). 
- The state could begin by conducting a survey of the food industry regarding compliance that is not yet a legal requirement. Even just formally surveying the industry would raise the awareness of the issue. The results of the 'non-compliance' survey could be data used for prioritizing regular food safety inspections. Just formally surveying the industry would raise the awareness of the issue. Answers could be confirmed by standards or certification bodies. The state could leverage current industry awareness and compliance by asking additional questions such as:

o Do you follow a Food Fraud standard or certification? Which one?

o Do you have Food Fraud audits that certify your operations? Who conducts the audits? (As previously noted, FSMA has a section that specifically regulates accredited third-party auditors and GFSI was not endorsed but was noted asking these questions is aligned with FDA activities.)

- The State could consider survey results when setting food industry inspection frequency.

\subsubsection{Prevention}

There should be a process to review the intervention and response to consider the impact on prevention. This step is 'Prevention' which could be formalized by development of a Food Fraud Prevention Plan (FFPP). Often current or recent intervention efforts can be expanded to increase the impact on preventing Food Fraud. For example, if species testing were increased then notifying the industry of this would also raise fraudster awareness and have a deterrent effect. If such testing were kept secret, then the results would simply be detecting suspect product and not preventing Food Fraud. To reiterate the point, the goal is not to catch product but prevent Food Fraud from occurring in the first place.

\subsubsection{Implementation and Management}

Implementation and Management include raising awareness as well as the ongoing support and encouragement of the prevention activities.

- Education, Training, and Awareness: Education is foundational and theoretical concepts that form the logic for laws, regulations, and activities. Training is actual activities that will need to be conducted. Finally, awareness can be supported by brief documents that provide an overview of the intent, definitions, and expectations. The available education products and methods should be used assuming adequate capacity and efficacy.

- Implementation and Management: Until there is more information and experience the implementation of the programs and ongoing management should be recommended by the task force.

\subsubsection{Next Steps for Technology}

This research introduces a process and prevention plan. This does not yet include or recommend countermeasures or control systems. Selecting effective and efficient countermeasures or systems are very specific to a fraud opportunity and food supply chain. The selection should consider macro-economic trends such as global commodity price fluctuations and also micro-economic factors such as vulnerability of product transported through an unregulated free trade zone. Also, the most direct impact on the fraud opportunity is individual factors for the local fraudster and the customer who is receiving the products. For maximum product protection the laws and inspections should provide flexibility in the application of science and technology for countermeasures or control systems.

\section{Conclusion}

Food Fraud is a complex and interdisciplinary topic that is already addressed in various laws and regulations. Food Fraud is a topic that consumers expect government agencies to make sure is addressed whether by the governments themselves or by the producers, manufactures, distributors, and retailers. A government directly addressing Food Fraud - if only as a statement of the opinion that Food Fraud incidents are within legal scope - would reinforce industry efforts that are already underway. A government that either holistically addresses or even casual mentions Food Fraud adds more support for the current prevention plans and further helps to protect the food supply chain.

Several basic information gathering activities could have a great impact on prevention and require very few resources to implement. The reality is that State agencies need to meet the expectations of their citizens - and in the absence of clear Federal guidance - they may need to create these themselves. Through collaboration among academic and non-governmental organizations, general close engagement with citizens, narrower areas of focus, and fewer stakeholders, States can often be more efficient than the Federal level to quickly and efficiently implement programs. Food Fraud prevention could be implemented efficiently, effectively, and quickly at the state level to quickly make an impact on reducing the fraud opportunity. A State's Food Fraud Prevention Plan could be a model that is used by other States and up to the Federal level.

These concepts, plans and steps apply to enterprises whether they are countries or companies.

\section{Supplementary Material}

A Chinese language version of this article is available as Supplementary Material (via http://www.Ingentaconnect.com).

\section{Acknowledgements}

This work was conducted under the key job responsibilities of the authors. No additional funding was used for this research. Spink and Moyers conducted this research in support of their committee member roles on Michigan's Food \& Agriculture Protection and Defense Working Group. This work was co-funded by the Economic and Social Research Council and the Food Standards Agency (grant number ES/ M003094/1).

Received: January 14, 2016

[1] E. Anklam, 'A Joint effort to ensure the safety and integrity of our food', Conference on Food Fraud, European Commission, October 2014, Rome, http://ec.europa.eu/ dgs/health_food-safety/information_sources/ events/20141023-24_food-fraud-conference_ en.htm, 2014.

[2] Y.Wu, CFSA, Chinese National Center for Food Safety Risk Assessment, 'China Regulation and Perspectives to Address Food Fraud and Non-Food Ingredient Adulterant', Food Safety Summit 2015, Baltimore, Maryland, USA, 2015.

[3] J. Chen, CFSA, Chinese National Center for Food Safety Risk Assessment, 'Strategies for Ensuring Food Safety of Chinese Products fight against food fraud', Institute for Food Technologists (IFT) Annual Conference 2015, Chicago, Illinois, USA, 2015.

[4] FDA, US Food and Drug Administration, 'Current Good Manufacturing Practice, Hazard Analysis, and Risk-Based Preventive Controls for Human Food', Federal Register, Docket NumberFDA-2011-N-0920, Wednesday, November 18, 2015, Accessed December 5, 2015, https://www.federalregister.gov/ articles/2015/11/18/2015-29340/current-goodmanufacturing-practice-hazard-analysis-andrisk-based-preventive-controls-for-human, 2015.

[5] 'Economically Motivated Adulteration' (EMA) was defined by the FDA in a 2009 Federal Register notice of a public meeting notice. EMA was defined as a 'substance' for 'economic gain' having a 'health hazard.' The FSMAPC did not explicitly reiterate that definition and no additional clarification was given. The rule mentioned hazards from 'economically motivated' acts which is a broader definition than only adulterant-substances. Also, FSMAPC referred to an 'agent' (presumably meant 'physical agent') that was the cause of the health hazard. Pathogenic spoilage from genuine stolen products that have been mishandled could be the 'agent.' In this case the stolen product was the 'economically motivated' act that led to the spoilage 'agent." The 'agent' was $\boldsymbol{n o t}$ intentionally added for economic gain. Nevertheless, it appears any 'economically motivated'act that leads to a hazard agent is a violation of this section of FSMA-PC. 
[6] Gao, US Governmental Accountability Office, 'Food and Drug Administration, Better Coordination Could Enhance Efforts to Address Economic Adulteration and Protect the Public Health', in 'Report to Congressional Requesters', October 2011, GAO-12-46, United States Government Accountability Office, GAO, GAO-12-46, 2011.

[7] CRS, US Congressional Research Service, 'Food Fraud and Economically Motivated Adulteration', 2014.

[8] M. Robach, 'Food Safety Management Innovation', China Focus Day, Global Food Safety Initiaive, Beijing, November 2014, http://www.infoexevents.com.cn/gfsichina/, 2014.

[9] J. Spink, D. C. Moyer, J. Food Science 2011, 76, R157.

[10] DEFRA, U.K. Department for Environment, Food, and Rural Affairs, 'Elliott review into the integrity and assurance of food supply networks', Independent report, Ref: PB14089, PDF, 539KB, 84 pages, https://www.gov. uk/government/uploads/system/uploads/ attachment_data/file/350726/elliot-reviewfinal-report-july2014.pdf, 2014.

[11] EC, European Commission, 'On the food crisis, fraud in the food chain and the control thereof', 2014.
[12] Global Food Safety Initiative, GFSI, 'GFSI Position on Mitigating the Public Health Risk of Food Fraud', 2014, Global Food Safety Initiative, Consumer Goods Forum.

[13] SSAFE, formerly known as the 'Safe Supply of Affordable Food Everywhere', is an industry sponsored non-governmental association.

[14] SSAFE, Safe Supply of Affordable Food Everywhere, "Guideline for food fraud vulnerability self-assessment UNCIRCULATED DRAFT', 2015.

[15] FDA, US Food and Drug Administration, Public Meeting: Economically Motivated Adulteration. 2009, http://www.fda.gov/ NewsEvents/MeetingsConferencesWorkshops/ ucm163619.htm.

[16] J. Spink, D. C. Moyer, H. Park, J. A. Heinonen, Crime Science 2014, 3, 1.

[17] J. Spink, D. C. Moyer, H. Park, J. A. Heinonen, Crime Science 2013, 2, 1.

[18] J. Spink, 'A study of the variables affecting the heat seal strength and hot tack of ethylenevinyl acetate heat sealant copolymers', 1992, Michigan State University: United States -Michigan.

[19] M. Felson, R. Boba, 'Crime and Everyday Life', 4th ed., Sage Publications, 2010.

[20] R. V. Clarke, 'Situational Crime Prevention', Chap. 1: 'Introduction, in Situational Crime Prevention', Ed. R.V. Clarke, 1997, Harrow and Heston Publishers: Guilderland, NY.
[21] R. Clarke, J. Eck, 'Crime Analysis for Problem Solvers in 60 Small Steps-Step 35'. Center for Problem Oriented Policing. Washington, DC: US Department of Justice Office of Community Oriented Policing Services, 2005, p. 68.

[22] R. V. Clarke, J. E. Eck, 'Crime analysis for problem solvers', Washington, DC, Center for Problem Oriented Policing, 2005.

[23] R. Sampson, J. E. Eck, J. Dunham, Security Journal 2010, 23, 37.

[24] GMA, Grocery Manufacturers Association. 'Consumer Product Fraud', 2010, cited 2012, http://www.gmaonline.org/publications/ consumerproductfraud.pdf.

[25] J. Spink, J. Intellectual Property Rights 2011, $16,183$.

[26] J. C. Spink, C. Elliott, K. Swoffer, J. Inst. Food Science Technol. 2013, 27, 27.

[27] J. Spink, Chap. 9: 'Overview of the Selection of Strategic Authentication and Tracing programs', in 'Identification and Analysis of Counterfeit and Sub-standard Pharmaceuticals', Eds A. I. Wertheimer, P. G. Park, 2012, ILM Publications, a Division of International Labmate Limited, London, p. 154.

[28] A first-party audit is done internally by the actual food company and a second-party audit is conducted by a consultant to provide recommendations to the company.

[29] J. Spink, D. C. Moyer, M. Rip, J. Forensic Sci. Criminol. 2016, in press. 